\title{
Synthesis of thioarsenate compounds and their occurrence characteristics in groundwater
}

\author{
SHUTANG SUN ${ }^{1}$ AND XIANJUN XIE ${ }^{2}$
}

${ }^{1}$ China University of Geosciences (Wuhan)

${ }^{2}$ School of Environmental Studies, China University of Geosciences (Wuhan)

Presenting Author: shutangsun@cug.edu.cn

As an important occurrence form of arsenic in sulfur-rich water, thioarsenate plays a very important role in its migration and transformation. However, the standard synthesis method of thioarsenate is complex and the occurrence characteristics and influencing factors in low temperature groundwater are rarely reported. In this study, the standard reference material of thioarsenate was synthesized by hydrothermal method, hydrothermal reactions of $\mathrm{As}(\mathrm{III})$ and $\mathrm{As}(\mathrm{V})$ with sulfides and element sulfur in different proportions, the results showed that under the ratio of $\mathrm{As}(\mathrm{III})$ and elemental sulfur at 3:1, the content of arsenic monothioarsenate was up to $75 \%$, and the content of arsenic dithioarsenate increased gradually with the increase of sulfur. The analytical method of thioarsenate based on HPLCICPMS was established. The detection limit of this method was $0.01 \mu \mathrm{g} / \mathrm{L}$. The effects of different preservation conditions on the stability of thioarsenate compounds were discussed. The above method was used to analyze thioarsenate in groundwater in Datong Basin. The results showed that thioarsenate was detected in $40 \%$ of the water samples, and the highest concentrate was $209.90 \mu \mathrm{g} / \mathrm{L}$. The weak alkaline reduction condition is beneficial to the occurrence of thioarsenate, and the sulfide concentration plays an important role in controlling the formation of thioarsenate. The in-depth study of thioarsenate in groundwater is helpful to reveal the law of migration and transformation of arsenic in sulfur-rich groundwater and is of great significance to enrich the genetic theory of high-arsenic groundwater. 